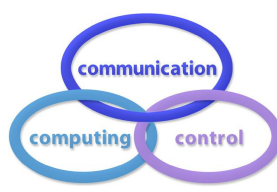

\title{
Automatic Flood Detection in Multi-Temporal Sentinel-1 Synthetic Aperture Radar Imagery Using ANN Algorithms
}

\author{
A. Nallapareddy, B. Balakrishnan
}

\author{
Anusha Nallapareddy* \\ Sathyabama Institute of Science and Technology \\ Chennai, 600119, India \\ *Corresponding author: anusha.nallapareddy@gmail.com \\ Bharathi Balakrishnan \\ Sathyabama Institute of Science and Technology \\ Chennai, 600119, India \\ E-Mail: bharathivaradhu@gmail.com
}

\begin{abstract}
Natural Calamities like floods cause wide-range of damage to human existence as well as substructures. For automatic extraction of flooded area in multi-temporal satellite imagery acquired by Sentinel-1 Synthetic Aperture Radar (SAR), this paper presents two neural network algorithms: Feed-Forward Neural Network, Cascade-forward back-propagation neural network. This work currently focuses on Uttar Pradesh in India, which was affected due to floods during August 2017. The two models are trained, validated and tested using MATLAB R2018b. The models are first trained using a variety of input data until the percentage of error with respect to water body detection is within an acceptable error limit. These models are then used to extract the water features effectively and to detect the flooded regions. Finally, flood area is calculated in sq. $\mathrm{km}$ in during flood and post-flood imagery using these algorithms. The results thus obtained are compared with that from the binary thresholding method from previous studies. The results show that the FeedForward Neural Network gives better accuracy than the Cascade-forward back propagation neural network. Based on the promising results, the proposed method may assist in our understanding of the role of machine learning in disaster detection.
\end{abstract}

Keywords: Flood, Machine learning, Neural network, Satellite, Synthetic Aperture Radar.

\section{Introduction}

Environmental calamities caused by weather variations can source above $\$ 500$ billion damages [47] impacting humans, substructures and earth's atmosphere [19, 28]. Floods are one of the recurrently befalling environmental disasters [27]. The momentary enclosing of terrestrial by water which is not usually enclosed by water is termed as 'flood' which is stated by the European Union (EU) floods decree [46]. During monsoon season, substantial ejection commencing from watercourses sources extensive 
range floods [2]. When a river catchment obtains water from rain, unfreezing snowflakes or snow beyond its capacity [46], river or rivirine overflowing generally befalls [27].

Over the preceding limited centuries, the Indian Himalayan expanse oversaw unparalleled flooding, aimed at the case in point Ganga River Floods in 2010 [3], Brahmaputra Floods in 2012 [5], and Jhelum Floods in 2014 [4]. Dense shower aimed at an extended period and massive input of water from upstream sources trigger floods [26]. The flood data can be sourced from in-situ, aerial or satellite imagery [17]. The flood level determined via in-situ can remain impractical, imprecise and expensive [6]. Despite being pricey towards attaining the airborne images, they also have limited spatial and temporal resolution [9]. The gauge stations extent the water elevation but not the level of flood [19]. The satellite broadcasting images define the level of flooding above huge terrestrial zones casing unreachable extents in recurrent interludes of period [3]. When the flood event occurs, the satellite can be programmed to collect the flooded area information. It also facilitates a long-lasting record and retrieval of such data [31].

\section{Literature review}

Flood detection using remote sensing imagery comprises of information collecting, data extraction and examination, managing and integration using additional information bases as well as statistics constancy. Asia is extremely inflated with respect to large-scale natural disasters in comparison to other continents over the preceding eras, according to universal statistics [35].Of the global aggregate, disasters occurring in Asia comprise 39\% [18]. Numerous researchers in literature have presented various approaches for water body extraction from multi-sensor remote sensing images and have utilized this retrieved information to depict water distribution, often termed as 'inundation'detection, 'water mask' derivation, 'or 'water body' or 'flood mask' extraction [21]. The water bodies can either be permanent water surfaces such as lakes, ponds, rivers, etc., or temporarily inundated areas. However, all the temporarily inundated wetland areas cannot be addressed as flooded. The term "flood" is usually used, if the temporarily inundated wetland area is impacting the livelihood of mankind, causing damage to the infrastructure, etc., Flood is a dramatic and one of the recurring natural disasters which affects several areas in the world often causing loss of lives and damage to properties [10]. Precise flood mapping is imperative to flood impact assessment and disaster management.

Satellite imagery can capture massive surface ground area in a single image [1]. Hence flood detection using satellite imagery is the most sought after method. Challenges exist in the derivation of water surface from both optical as well as microwave data [21]. Most authors prefer to derive 'water mask' from optical data such as those from MODIS, IKONOS, QUICKBIRD, SPOT, Sentinel-2A/2B, Landsat and AWiFS [24] and AVHRR/3. Derivation of water surface using optical data is hindered by the fact that the earth's surface imagery cannot be acquired during cloud-coverage. This is one of the main drawbacks, as the cloud cover is ubiquitous during rainy season, and often prevails during flood situations [24]. However, if the image acquired is not impeded by the cloud cover, optical data enables derivation of water surfaces, including characteristics related to water, such as turbidity [13], dissolved colored organic content [7], and water depth in clear and shallow water areas [21]. These are impossible to achieve using the microwave data [8, 15, 21].

Several authors and studies have determined that [21] remote sensing Synthetic Aperture Radar (SAR) imagery is a beneficial source of information for water detection during occurrence of floods [10] based on sensors such as RADARSAT-1/2, COSMO-SkyMed, Sentinel-1A/1B/1B , ALOS PALSAR, ENVISAT ASAR and TerraSAR-X(TSX) [21, 24]. Smooth water or calm body of water appears very distinct in SAR imagery hindering diffuse reflection [21]. The ground surface which is covered by smooth water yields very low to no backscattering, and thus it appears as very dark to purely black regions in SAR imagery. Due to its longer wavelength, the microwaves can penetrate through clouds, rain droplets, water vapor, and aerosol layers. This allows for observation by the SAR sensors even during cloud-covered conditions. No matter which sensor, remote sensing is the best tool for water detection [21]. The extracted 'water mask' can be concluded as either temporarily inundated wetland area or severe flood, usually based on the additional information such as loss of human lives, agriculture crops damages, roads and building damages etc., Prompt action is imperative to successfully manage 
natural disasters like floods [1].

In the literature, the authors have mainly focussed on change detection occurring due to disasters, depending only on sensors [32] and used the suitable image processing techniques [22] such as image algebra (band differencing and band rationing) [30], post-classification comparison and object-based change detection method [11]. In recent years researchers are focusing on machine learning techniques for accurate automatic detection of the disaster region compared to the normal methodologies adapted previously $[1,10]$. Due to the frequent occurrence of natural disasters, detection of the disaster area has gained a great attention [10]. Artificial Neural Networks (ANNs) are excellent tools that are capable of finding meaningful solutions to the engineering problems which are too complex for the human programmers to teach the machine to recognize the patterns [10,33]. Even when the input data is incomplete and contains errors, ANNs give solutions by learning and generalizing from examples and experience. Different types of neural networks can be created by giving different types of connections among the nodes. However, the most common type of connection is the layered connection i.e., with input, hidden and output layers. In order to improve the accuracy of water-body detection, in this study, two different ANN approaches are implemented namely Feed-forward Neural Network and Cascade-forward back-propagation neural network for detection of the disaster region using multitemporal Sentinel-1 satellite imagery acquired before, during and after occurrence of floods in August 2017.

\section{Study area and data used}

This section discusses the study area and the data set used in the study of flood area detection. The Sentinel-1 SAR data captured during August 2017 floods in the state of Uttar Pradesh, India throw light on water body extent and flooded area [22]. The study area chosen corresponds to few districts of Uttar Pradesh, India where River Rapti merges into River Ghaghara. The location map of the study area is shown in the Figure 1. Geographically the study area lies between $83^{\circ} 14^{\prime} 52.07^{\prime \prime}$ East to $84^{\circ} 10^{\prime} 25.78$ " East latitude and $26^{\circ} 0^{\prime} 38.89^{\prime \prime}$ to $26^{\circ} 45^{\prime} 45.21^{\prime \prime}$ North longitude. Uttar Pradesh

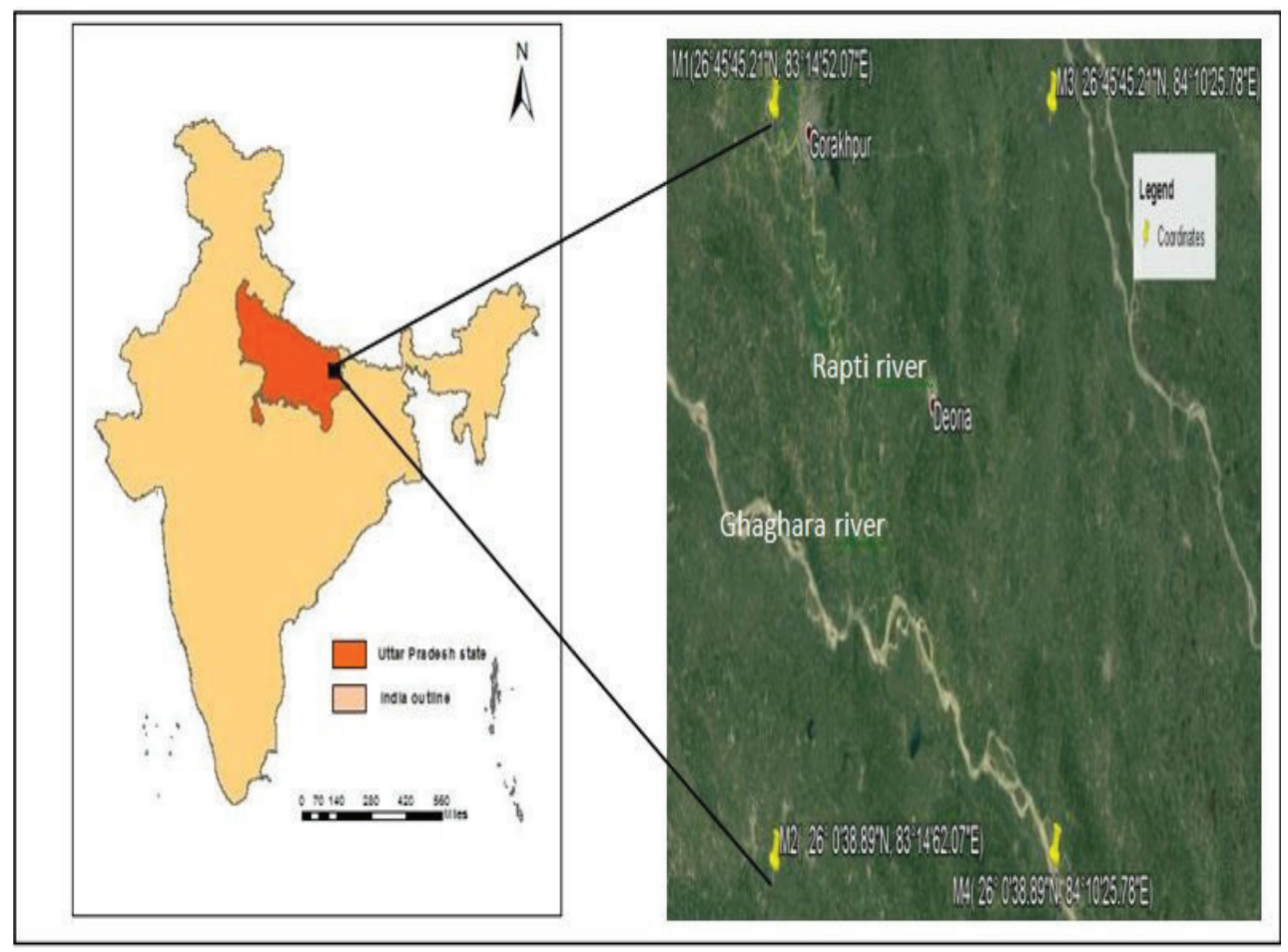

Figure 1: Location map of the study area (Source: Google map)

is one of the states in India affected by rivirine floods almost every year. Rivirine or fluvial flooding occurs when excessive rainfall over an extended period of time causes a river to exceed its capacity [20]. Uttar Pradesh state lies in the Northern part of India and it falls within the periphery of "Indian 
Flood Prone Areas" [42]. Heavy rains occur during the summer monsoon from June to September and the glaciers provide their greatest amount of water to the rivers during the same period [43]. Due to heavy rainfall in August 2017, river flooding has affected around 3097 villages in 24 districts of Uttar Pradesh state in India [41].

River levels increased after heavy rainfall on 10th August 2017 in parts of the Uttar Pradesh state and river catchments in Nepal. This has resulted in devastating floods over the following days. As per the media report on $25^{\text {th }}$ August 2017, owing to the pressure exerted by overflowing Rivers Rapti, Rohini and Ghaghara, two dams were damaged in the Gorakhpur district of Uttar Pradesh, India [44]. This has worsened the flood situation. River Rapti is a tributary of Ghaghara River and Ghaghara River is one of the main left bank tributaries of River Ganga. According to CWC (Central Water Commission) reports, various Rivers were reported to be in spate due to rise in the water level, thus causing flood in many districts of Uttar Pradesh [2]. According to National Disaster Response Force (NDRF) reports, Gorakhpur is one of the most affected districts.

For flood detection and comparison, three categories of SAR images acquired by Sentinel-1 at different intervals were used in this study. One is pre-flood image (refer Table 1) and the next category is during-flood images (refer Table 2, Table $3 \&$ Table 4) and the third category is post-flood image (refer Table 5).

Table 1: Imaging information from Sentinel-1 used in this study (Dataset1)

\begin{tabular}{|c|c|}
\hline Product name & $\begin{array}{l}\text { S1B_IW_GRDH_1SSV_20170211T001858 } \\
\text { 20170211T001924_004245_0075C7_5879.SAFE }\end{array}$ \\
\hline Satellite & Sentinel-1B \\
\hline Beam/Mode & Interferometric Wide (IW) swath \\
\hline Product type & Ground Range Detected (GRD) \\
\hline Resolution class & $\operatorname{High}(\mathrm{H})$ \\
\hline Processing level & 1 \\
\hline Product class & Standard (S) \\
\hline Polarization & Single VV (SV) \\
\hline Start Date/Time & $11^{\text {th }}$ of February 2017 at $00: 18: 58$ \\
\hline Stop Date/Time & $11^{\text {th }}$ of February 2017 at $00: 19: 24$ \\
\hline Pass & Descending \\
\hline Pixel * pixel spacing & $10 \mathrm{~m} * 10 \mathrm{~m}$ \\
\hline Polarization & Vertical Transmit-Vertical Receive (VV) \\
\hline
\end{tabular}

Table 2: Imaging information from Sentinel-1 used in this study (Dataset2)

\begin{tabular}{|l|l|}
\hline Product name & $\begin{array}{l}\text { S1A_IW_GRDH_1SDV_20170813T122948 } \\
\text { 20170813T123013_017905_01E071_F531.SAFE }\end{array}$ \\
\hline Satellite & Sentinel-1A \\
\hline Beam/Mode & Interferometric Wide (IW) swath \\
\hline Product type & Ground Range Detected (GRD) \\
\hline Resolution class & High $(\mathrm{H})$ \\
\hline Processing level & 1 \\
\hline Product class & Standard (S) \\
\hline Polarization & Dual VV+VH (DV) \\
\hline Start Date/Time & $13^{\text {th }}$ of August 2017 at 12:29:48 \\
\hline Stop Date/Time & $13^{\text {th }}$ of August 2017 at 12:30:13 \\
\hline Pass & Ascending \\
\hline Pixel * pixel spacing & $10 \mathrm{~m}{ }^{*} 10 \mathrm{~m}$ \\
\hline Polarization & Vertical Transmit-Vertical Receive (VV) \\
\hline
\end{tabular}


Table 3: Imaging information from Sentinel-1 used in this study (Dataset3)

\begin{tabular}{|l|l|}
\hline Product name & $\begin{array}{l}\text { S1A_IW_GRDH_1SDV_20170825T122949 } \\
\text { 20170825T123014_018080_01E5C1_50D7.SAFE }\end{array}$ \\
\hline Satellite & Sentinel-1A \\
\hline Beam/Mode & Interferometric Wide (IW) swath \\
\hline Product type & Ground Range Detected (GRD) \\
\hline Resolution class & High (H) \\
\hline Processing level & 1 \\
\hline Product class & Standard (S) \\
\hline Polarization & Dual VV+VH (DV) \\
\hline Start Date/Time & $25^{\text {th }}$ of August 2017 at 12:29:49 \\
\hline Stop Date/Time & $25^{\text {th }}$ of August 2017 at 12:30:14 \\
\hline Pass & Ascending \\
\hline Pixel * pixel spacing & $10 \mathrm{~m} * 10 \mathrm{~m}$ \\
\hline Polarization & Vertical Transmit-Vertical Receive (VV) \\
\hline
\end{tabular}

Table 4: Imaging information from Sentinel-1 used in this study (Dataset4)

\begin{tabular}{|l|l|}
\hline Product name & $\begin{array}{l}\text { S1A_IW_GRDH_1SDV_20170828T001939 } \\
\text { 20170828T002004_018116_01E6D5_AB09.SAFE }\end{array}$ \\
\hline Satellite & Sentinel-1A \\
\hline Beam/Mode & Interferometric Wide (IW) swath \\
\hline Product type & Ground Range Detected (GRD) \\
\hline Resolution class & High (H) \\
\hline Processing level & 1 \\
\hline Product class & Standard (S) \\
\hline Polarization & Dual VV+VH (DV) \\
\hline Start Date/Time & $28^{\text {th }}$ of August 2017 at 00:19:39 \\
\hline Stop Date/Time & $28^{\text {th }}$ of August 2017 at 00:20:04 \\
\hline Pass & Descending \\
\hline Pixel * pixel spacing & $10 \mathrm{~m}{ }^{*} 10 \mathrm{~m}$ \\
\hline Polarization & Vertical Transmit-Vertical Receive (VV) \\
\hline
\end{tabular}

Table 5: Imaging information from Sentinel-1 used in this study (Dataset5)

\begin{tabular}{|l|l|}
\hline Product name & $\begin{array}{l}\text { S1A_IW_GRDH_1SDV_20170909T001939 } \\
\text { 20170909T002004_018291_01EC31_DF22.SAFE }\end{array}$ \\
\hline Satellite & Sentinel-1A \\
\hline Beam/Mode & Interferometric Wide (IW) swath \\
\hline Product type & Ground Range Detected (GRD) \\
\hline Resolution class & High $(\mathrm{H})$ \\
\hline Processing level & 1 \\
\hline Product class & Standard $(\mathrm{S})$ \\
\hline Polarization & Dual VV+VH $(\mathrm{DV})$ \\
\hline Start Date/Time & $09^{\text {th }}$ of September 2017 at 00:19:39 \\
\hline Stop Date/Time & $09^{\text {th }}$ of September 2017 at 00:20:04 \\
\hline Pass & Descending \\
\hline Pixel * pixel spacing & $10 \mathrm{~m} * 10 \mathrm{~m}$ \\
\hline Polarization & Vertical Transmit-Vertical Receive (VV) \\
\hline
\end{tabular}


The pre-flood and the post-flood images help in the overall flood assessment. Comparing the preflood image with the during-flood images helps to evaluate the flood until that point in time. The Sentinel-1 is a C-band SAR instrument operating at a central frequency of $5.404 \mathrm{GHz}$ [39]. Sentinel 1A and 1B are near-polar, sun-synchronous orbit satellites with a revisit cycle of 12-days [37]. With both these satellites operating the revisit cycle comes down to 6 days [37]. Sentinel-1 data products are distributed by European Space Agency (ESA) using a Sentinel-specific variation of the Standard Archive Format for Europe (SAFE) format specification [38]. The images used are Level-1 multi-looked and Ground Range Detected (GRD) [40] high resolution data products projected to ground range using the Earth ellipsoid model WGS84 (World Geodetic System) [36]. All the images are acquired in Interferometric Wide (IW) swath mode with same spatial and spectral resolutions on different dates and are of Vertical Transmit-Vertical Receive (VV) polarization. In the following sections, the methodological background and design of the two machine learning approaches are presented.

\section{Methodology}

The objective of this work is to extract the water layer and flooded area from the satellite imagery acquired by Sentinel-1 using neural network algorithms. In recent years, many researchers have been implementing machine learning algorithms for accurate automatic detection of the disaster region instead of normal methodologies like image differencing, image algebra, post-classification comparison and object-based change detection [1]. Two different neural network algorithms namely Feed-Forward Neural Network and Cascade-forward back-propagation neural network are implemented in this work for detection of the flood region using multi-temporal satellite imagery acquired before, during and after occurrence of floods. All the images are acquired with same spatial and spectral resolutions on pre-flood, during flood and post flood dates.

A visual check is carried out on each collected sample flood imagery in order to determine the visibility of flooding [14]. For flood inundation mapping, the pre-processing steps like sub-setting, geometric rectification and speckle noise removal were carried out by creating a batch processing in Erdas imagine tool. Batch processing allows processing chain by creating a graph and can be applied on the set of images. Sub-setting of the image is carried by selecting the Area of Interest (AoI) around the river where the flooding has occurred, to reduce the process time. Geometric rectification was performed by designating the pre-flood image captured on $11^{\text {th }}$ February 2017 as the master image and other images as the sensed images. It is a crucial step in change detection applications. It is the mechanism of geometrically aligning multiple images of the same scene into a single integrated image [12]. Speckle noise is a random noise and is one of the inherent characteristic of the SAR imagery which reduces the quality of the image $[23,24,25]$. Hence applying filtering techniques for suppression of this kind of noise and obtaining a smoother image is a typical pre-processing step, to improve the results in later stages of processing $[12,24]$.Various techniques have been proposed in the literature to diminish this kind of noise. This study uses $3 \times 3$ kernel size median filter, as it achieves better noise reduction by preserving the image details $[23,24,25]$.

The proposed system mainly consists of three stages namely training phase, validation phase and testing phase. For this study, the focus is on the floods that occurred on August 2017 in Uttar Pradesh, India. The data set is divided into 60:40 i.e., $60 \%$ of data for training and in the remaining $40 \%$ of data, $20 \%$ is used for validation and $20 \%$ for the testing. In neural networks, for obtaining better results, the model needs to be first trained with labeled data.

\subsection{Training phase}

In the training phase, the system is made to learn the features and characteristics of the disaster impacted geographical area. Neural networks can be trained to solve problems that are difficult for conventional computers or human beings. The training phase of the neural network is shown in Figure 2. In the training phase, the user provides the inputs manually and trains the system. The system will learn the features that the user provides. When a new input is given to the system during testing phase, it can recognize the features automatically with better precision. The training set is used to build the model. This contains a set of data that has pre-classified target and predictor variables. 


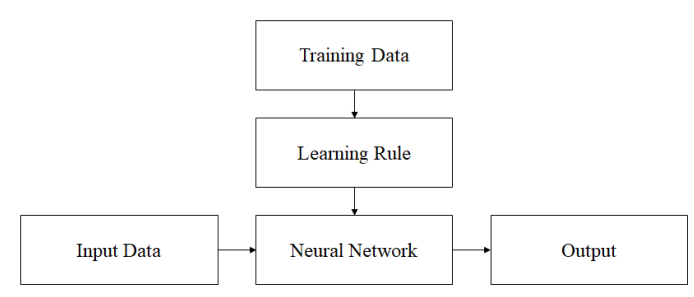

Figure 2: Training Phase of the Neural Network

The Feed-Forward Neural Network and Cascade-forward back-propagation neural network are implemented using MATLAB R2018b with sigmoid hidden neurons and linear output neurons as shown in the Figure 3 and Figure 4 respectively. Feed-Forward Neural Network and Cascade-forward back-propagation neural network are classes of multi-layer neural networks, which consist of series of layers called input, hidden and output layers. The information of the neural network will be stored in the form of weights and bias. The extracted features are given as input labelled data to the neural network for training. The network will be trained by adjusting the weights $w_{0}, w_{1}, w_{2}, \ldots, w_{15}$ in the hidden layer so that the error or the difference between the output produced in the output layer and the desired output is minimal. The number of neurons in hidden layer is fixed to 15 in the designed neural networks (refer Figures $3 \& 4$ ). There is a trade-off between time and accuracy. As the number of neurons in the hidden layer increase, the training will be good but it takes more time. Based on the application, the number of neurons should be decided, so that time taken is less and accuracy is more. Each neuron in the hidden and output layers will have weight and bias. In the learning process of neural network, weights are modified to correct the output. By using Levenberg-Marquardt backpropagation training algorithm the system is trained [16, 29, 34]. This training algorithm requires more memory but less time. The training algorithm automatically stops training the neural network, when generalisation stops improving which is indicated by an increase in the Mean Square Error (MSE) of the validation samples.

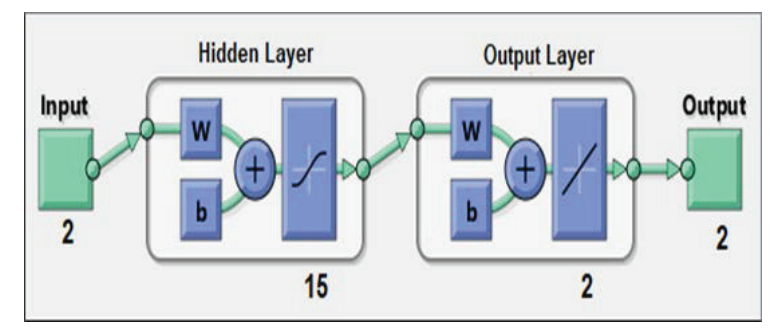

Figure 3: Feed-Forward Neural Network

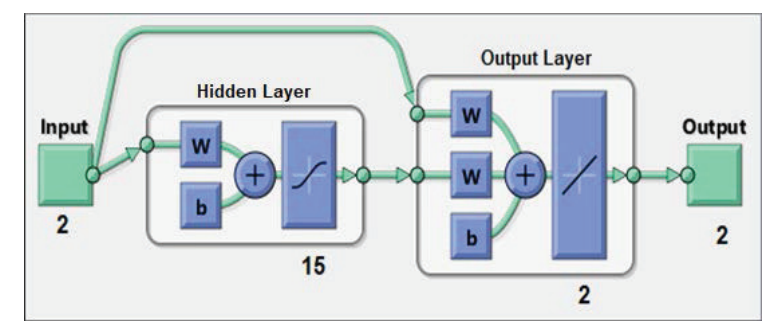

Figure 4: Cascade-forward back-propagation neural network

Training stage is very crucial in machine learning, as in this phase the model adjusts according to the errors. In the training phase, the system will learn all the features and characteristics from the input data sets the user provides i.e., tunes itself to the quirks of the training data sets. Input labeled data set is created by extracting and classifying the features present in the Sentinel-1 SAR satellite imagery. The extraction and classification of features is done by applying the binary thresholding method $[24,45]$. While selecting the threshold limit, care should be taken so that, it does not falsely 
classify the water as non-water and vice versa. Threshold $\mathrm{T}$ is set as 42 , permits separation of the features present in the Sentinel-1 satellite imagery into two classes.

\section{- Pseudocode:}

\section{For preparing training data}

\begin{tabular}{ll}
\hline Step 1: & Load the dataset \\
\hline Step 2: & $\begin{array}{l}\text { Check the pixel values of the image manually and apply binary thresholding method } \\
\text { if }(\mathrm{DN}<=\mathrm{T})=>\text { water; otherwise non-water. }\end{array}$ \\
& $\begin{array}{l}\text { Where, DN represents Digital Number or pixel value in SAR image, } \mathrm{T} \text { is threshold } \\
\text { limit/value }\end{array}$ \\
\hline Step 3: & $\begin{array}{l}\text { Generate labeled data file of the image i.e., defined the features as water/non-water } \\
\text { with respect to DN values of the image }\end{array}$ \\
\hline
\end{tabular}

For training the neural network

\begin{tabular}{ll}
\hline Step 1: & $\begin{array}{l}\text { Initialize the weights with adequate values; Input is taken from the training data } \\
\text { and the input is formatted as } \text { input, target }\}\end{array}$ \\
\hline Step 2: & Calculate the error from the difference between output and target \\
\hline Step 3: & Calculate the weight updates \\
\hline Step 4: & Adjust the weights to reduce the error \\
\hline Step 5: & Repeat Steps 2 to 4 for all training data i.e., iterate \\
\hline Step 6: & $\begin{array}{l}\text { Repeat steps } 2 \text { to } 5 \text { until the error reaches acceptable level i.e., till the best model } \\
\text { is found }\end{array}$ \\
\hline
\end{tabular}

\subsection{Validation phase}

After training the model and before going for testing, the model is validated using hold-out dataset or validation set i.e., the data set is used to compare the performances of the prediction algorithms that were created based on the training set. This phase facilitates early detection and correction of errors in the model to ensure accurate results in timely way and for choosing the algorithm that has the best performance.

\subsection{Testing phase}

Typically a hold-out dataset or test set is used to evaluate how well the model does with data outside the training set. The test set contains the pre-classified results data but they are not used when the test set data is run through the model until the end, where the pre-classified data are compared against the model results. The model is adjusted to minimize error on the test set.

\section{Experimental Results}

\subsection{Training phase}

In this work, the following two different types of machine learning algorithms are implemented using MATLAB R2018b for water surface extraction from Sentinel-1 satellite data:

- Feed-Forward Neural Network

- Cascade-forward back-propagation neural network

The objective of the neural network is to transform the inputs into meaningful outputs. Neural networks are composed of simple elements called nodes operating in parallel [45]. Connections or weights between the nodes largely determine the network function. Typically, neural networks are 
trained to perform a particular function by adjusting the values of the weights between nodes so that a particular input leads to a specific target output [10]. Figure 3 and Figure 4 illustrate such a network design, consisting of an input layer, hidden layer and an output layer. Here, the network is adjusted, based on a comparison of the output and the target, until the network output matches the target. Typically, many varieties of inputs are required to train a network.

The images selected for the flood area detection in this study are the microwave images captured by Sentinel-1and are shown in the Figures 5 (a), (b), (c),(d) \& (e). Due to diffuse reflection property, the smooth water pixels appear dark and due to specular reflection property, non-water pixels appear bright in the microwave images (refer Figures 5 (a), (b), (c), (d) \& (e)). The input data is sent to the training modules of Feed-Forward Neural Network, Cascade-forward back-Propagation neural network. The training process generates models which can classify the test images. The average training time of the Feed-Forward Neural Network is 3.5 seconds and for Cascade-forward back-propagation neural network is 1.2 seconds as shown in Figure 6 .

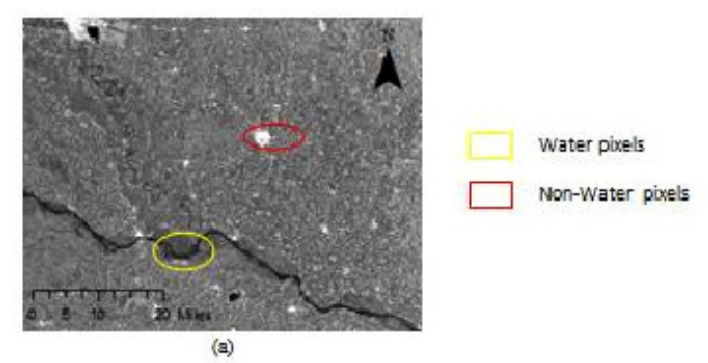

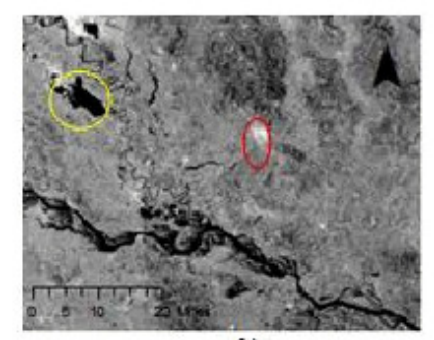

(b)

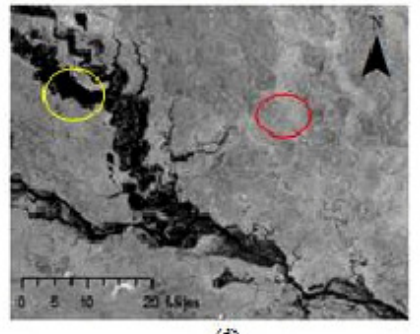

(d)

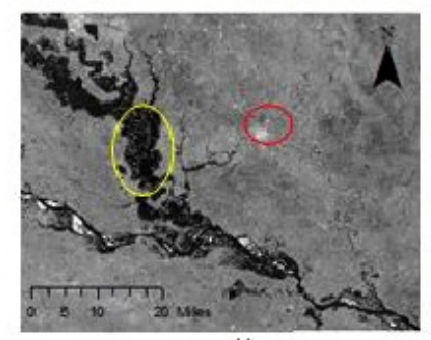

(c)

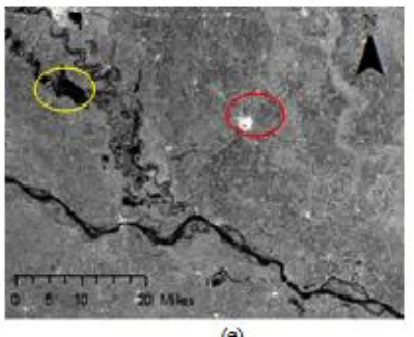

(e)

Figure 5: (a), (b), (c), (d) \& (e) - Input images acquired on $1^{\text {st }}$ February, $13^{\text {th }}$ August, $25^{\text {th }}$ August, $28^{\text {th }}$ August and $9^{\text {th }}$ September respectively

For training the network, the labeled input data is prepared by applying the binary thresholding technique. In the training phase, the neural networks are trained with Levenberg-Marquardt back propagation algorithm by giving the labeled data, desired output as inputs to the input layer [45]. The number of iterations depends on the performance of the network. Feed-Forward Neural Network is trained with 35 epochs and Cascade-forward back-propagation neural network is trained with 19 epochs as shown in training state plots (refer Figures 7 (a) \& (b)). Gradient Descent is an iterative optimization algorithm used in machine learning to find the best results (minima of a curve).The iterative quality of the gradient descent helps an under-fitted graph to make the graph fit optimally to the data. The Gradient descent has a parameter called learning rate. The process of learning Neural Network is called learning rule. An epoch is the number of iterations over the data set in order to train the neural network. Passing full dataset multiple times to the same neural network is iteration. To optimize the learning, the network is trained with scaled conjugate gradient back propagation. 
Gradient Descent is an iterative process. Therefore, updating the weights with single pass or one epoch is not enough. As the number of epochs increases, number of times the weights are changed in the neural network increases and the curve goes from under fitting to optimal to over fitting curve. The number of epochs is related to how diverse the data is.

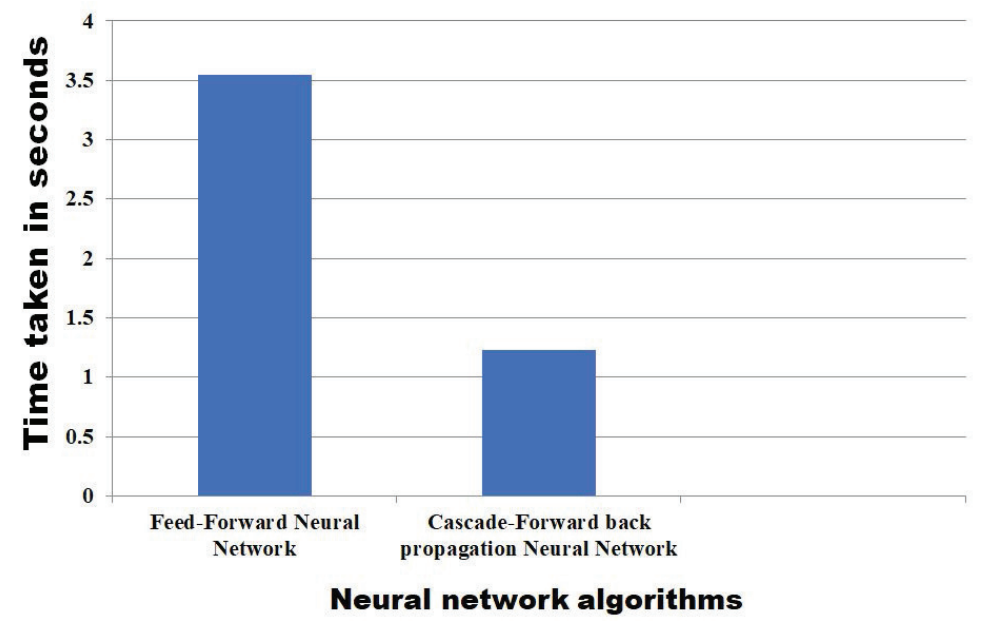

Figure 6: Average training time

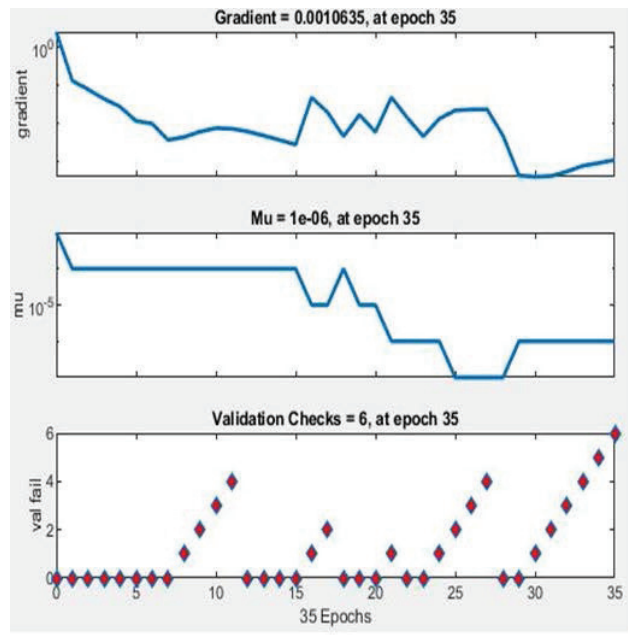

(a)

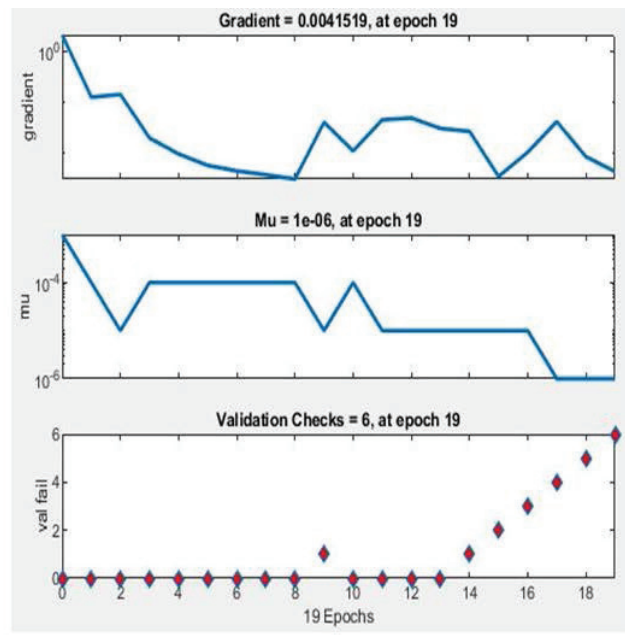

(b)

Figure 7: (a). Training state of Feed-Forward Neural Network and (b). Cascade-forward backpropagation Neural Network

After each iteration, error is checked. If the Mean Square Error (MSE) rate is maximum, the weights are adjusted and the network is trained until the error rate becomes minimum as shown in the performance plots of Feed-Forward Neural Network and Cascade-forward back- propagation network (refer Figures 8 (a) \& (b)). The plots (Figures 8 (a) \& (b)) show the best performance for training, validation, and test phases of the Feed-Forward and Cascade-forward back-propagation neural network plotted between MSE and epoch. As shown in the plots (refer Figures 8 (a) \& (b)), the error reduces after some epochs of training i.e., the networks' MSE drops rapidly when it learns, but might start to increase on the validation data set as the network starts over fitting the training data. The blue line (refer Figures 8 (a) \& (b)) shows the decreasing error in the training data. The green line (refer Figures 8 (a) \& (b)) shows the validation error. The training stops when the validation error starts increasing. The red line (refer Figures 8 (a) \& (b)) shows the error on test data indicating how well the network will generalize the new data. MSE is the average squared difference between outputs and the targets. Lower MSE values are desired and zero implies no error. Feed-Forward Neural Network MSE 
(refer Figure $8(\mathrm{a})$ ) is approaching ideal $(\sim 0)$ at 29 epochs. The Cascade-forward back-propagation neural network MSE (refer Figure $8(\mathrm{~b})$ ) is approaching ideal $(\sim 0)$ at 13 epochs, which is known as best validation performance with lowest validation error.

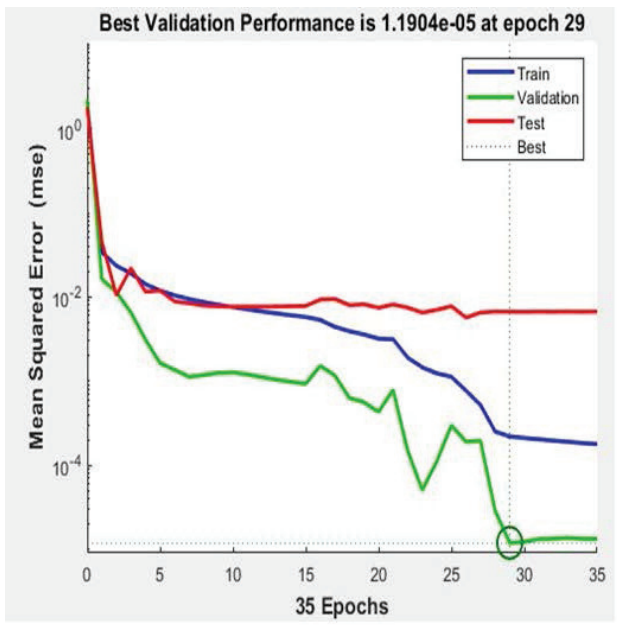

(a)

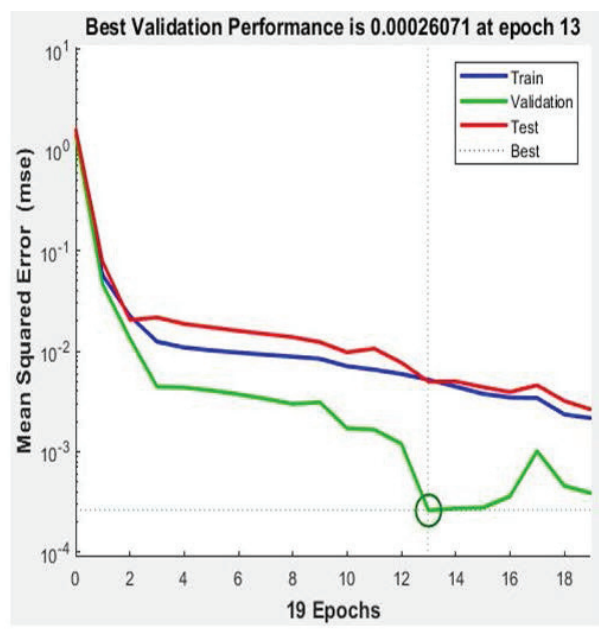

(b)

Figure 8: Performance plot of (a). Feed-forward neural network and (b). Cascade-forward backpropagation neural network

Regression(R) Analysis of Feed-Forward Neural Network and Cascade-forward back-propagation neural network is shown in Figure 8 (a) \& Figure 8 (b) respectively. It is the plot between the targets and the outputs. Regression $R$ values measure the correlation between the output and the target. An $\mathrm{R}$ value of 1 means a close relationship i.e., a very good accuracy, 0 a random relationship. FeedForward Neural Network model has a good training accuracy with R value 0.999120 (refer Figure 9 (a)) compared to Cascade-forward back-propagation neural network, whose $\mathrm{R}$ value is 0.979387 (refer Figure 9 (b)).
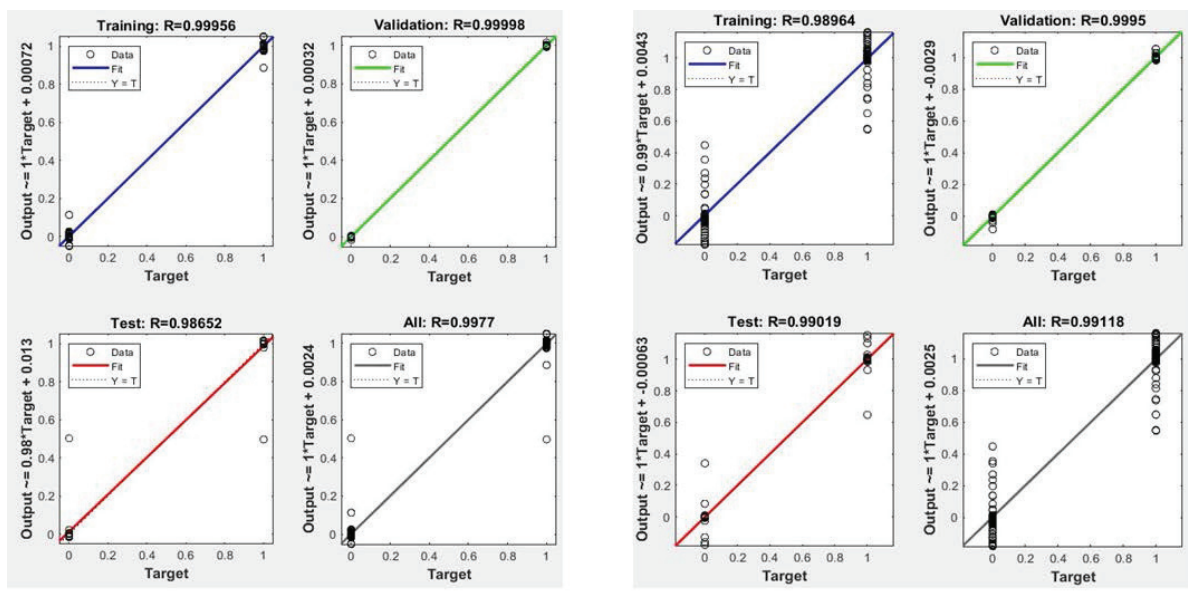

(a)

(b)

Figure 9: Regression (R) analysis of (a). Feed-forward neural network and (b). Cascade-forward back-propagation neural network

\section{$5.2 \quad$ Testing phase}

The testing phase is essential for evaluation of the performance of the system based on the extracted or detected disaster regions. The average testing time for Feed-Forward Neural Network is 0.68 seconds and for Cascade-forward back propagation Neural Network is 0.58 seconds as presented in 
Figure 10. The images used in this study are microwave images obtained by Sentinel-1 instrument in Interferometric Wide (IW) swath mode [11] (refer Figures 5 (a), (b), (c), (d) \& (e)). The machine learning algorithms are implemented in this study of a flood that occurred in Uttar Pradesh, India in August 2017. Based on the knowledge gained by the model in the training phase, it should be able to classify the features accurately as either water or non-water bodies, when a new input data is given [10].The expectation is that the highest prediction values with label 'water' should be extracted or highlighted as the disaster region. The research in this work focuses on detection of changes between i) pre-disaster imagery and during disaster imagery and ii) pre-disaster imagery and post- disaster imagery [1]. Detection of changes indicates the occurrence of disaster in that area.

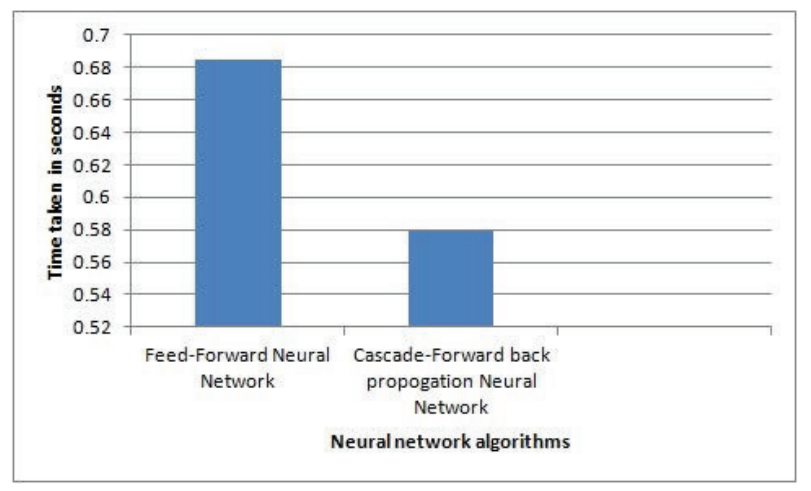

Figure 10: Average testing time

To reduce the speckle noise and to minimize classification errors, median filter of window size $3 \mathrm{x} 3$ is applied on pre-flood, during-flood and post-flood imagery [21]. In the study area, it can be observed that the water areas are relatively smooth and therefore appear dark in the imagery [21] (refer Figures 5 (a), (b), (c), (d) \& (e)). Water body extraction is rarely affected by water look-alike areas (refer Figures 5 (a), (b), (c), (d) \& (e)). The classification result strongly depends on the selected threshold value in areas of low contrast between open water surfaces and the surrounding non-water areas. The binary thresholding method is applied with threshold limit $\mathrm{T}<=42$ and the training data file is created [24]. From the pre-disaster imagery, the water mask of permanent water bodies such as river, pond is generated. The Sentinel-1A SAR data acquired during flood and post flood time provides information regarding water body extent and flooded area [25]. The system is trained, tested and the results obtained are shown in Figures 11 (a), (b), (c) \& (d); and Figures 13 (a), (b), (c) \& (d). The two neural network algorithms are observed to give similar results with respect to water layer extraction, which can be observed in Figures 11 (a), (b), (c) \& (d); and Figures 13 (a), (b), (c) \& (d).

Wherever water body is present in the during flood and post flood imagery, the two algorithms correctly identified and classified them as water. This is and highlighted in color(s) and is shown in Figures 11 (a), (b), (c) \& (d); and Figures 13 (a), (b), (c) \& (d). Then the extracted water permanent mask from pre-flood image is overlaid and only the flooded region is extracted from the during flood and post flood imagery as shown in the Figures 12 (a), (b), (c) \& (d) and Figures 14 (a), (b), (c) \& (d). Finally, from the resultant images, highlighted flooded area (in white color (refer Figures 12 (a), (b), (c) \& (d); and Figures 14 (a), (b), (c) \& (d))) is calculated in sq. km. as shown in the Table 6.

In the resultant image, flooded area and normal water area can easily be distinguished (refer Figures 12 (a), (b), (c) \& (d); and Figures 14 (a), (b), (c) \& (d)). When a natural calamity like flood occurs, a methodology which can give accurate and timely results with respect to flood area detection is required. For the flood area calculation purpose, results obtained from Binary thresholding technique using GIS tool are used as a reference. The flood area obtained by Feed-Forward Neural Network matches $97 \%$ with that from traditional method (Binary thresholding technique using GIS tool) (refer Table 7). Feed-Forward Neural Network algorithm is found to detect the flooded area with greater accuracy ( $97 \%$ ) when compared to the Cascade-forward back-propagation neural network (refer Figure $15)$. 

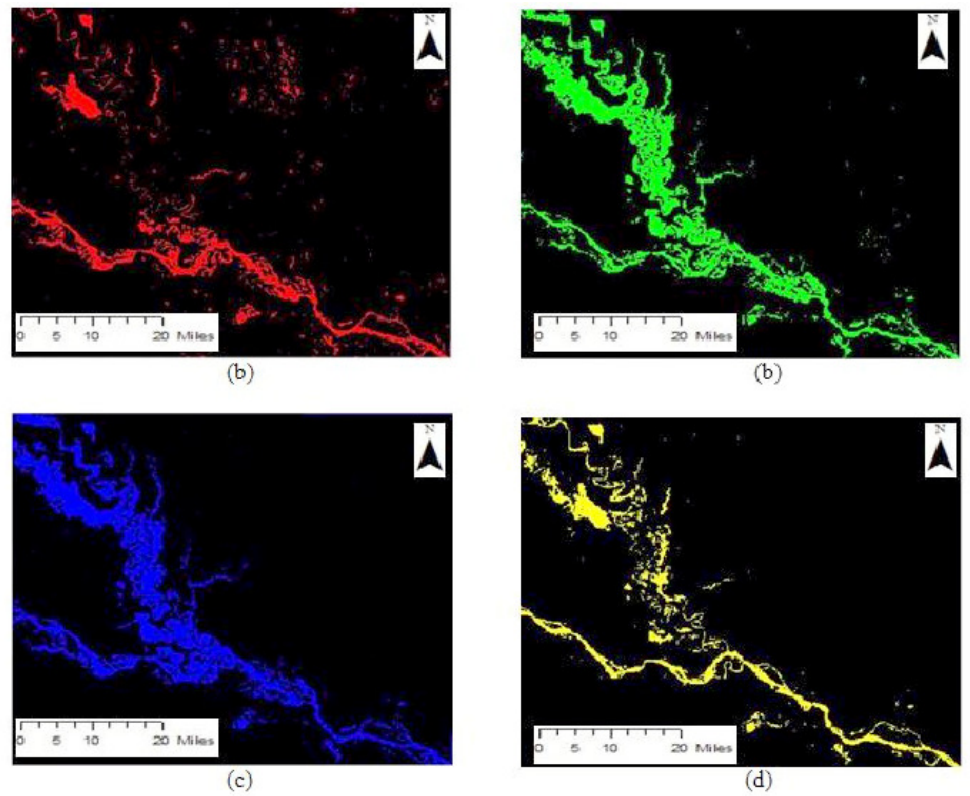

Figure 11: Water layer detection using feed-forward neural network on (a). $13^{\text {th }}$ August, (b). $25^{\text {th }}$ August, (c). $28^{\text {th }}$ August and (d). $9^{\text {th }}$ September 2017 respectively

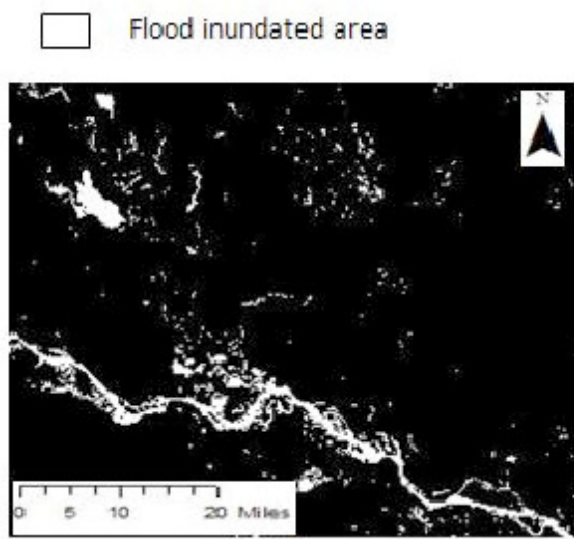

(a)
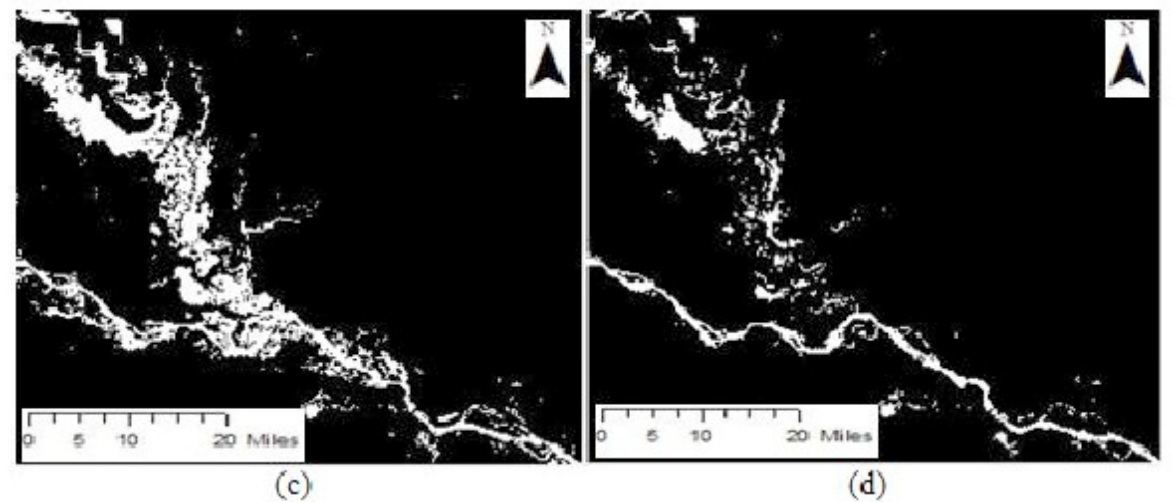

Figure 12: Flood area detection by feed-forward neural network on (a). 13 ${ }^{\text {th }}$ August, (b). $25^{\text {th }}$ August, (c). $28^{\text {th }}$ August and (d). $9^{\text {th }}$ September 2017 respectively 


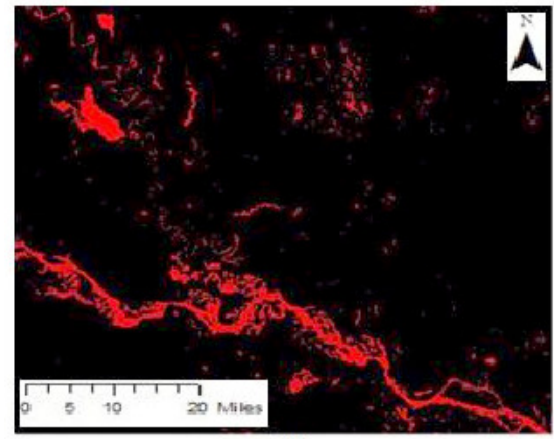

(b)

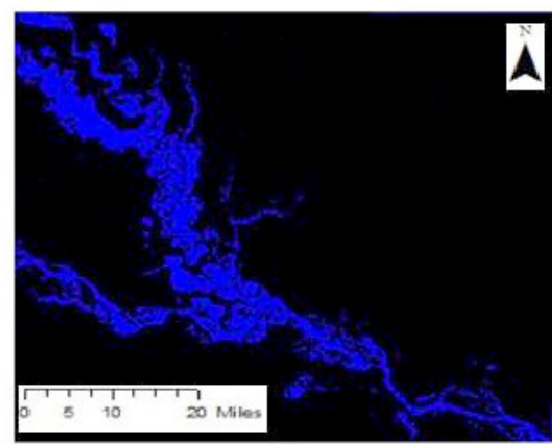

(c)

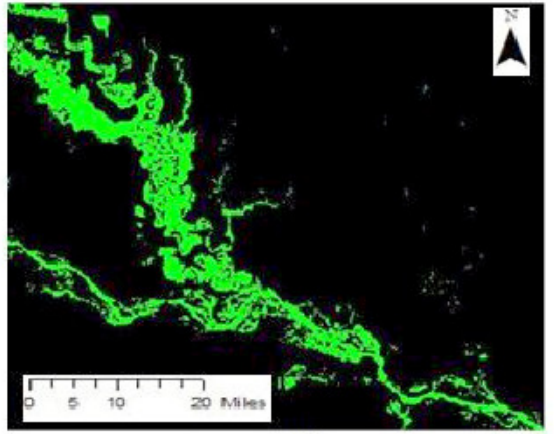

(b)

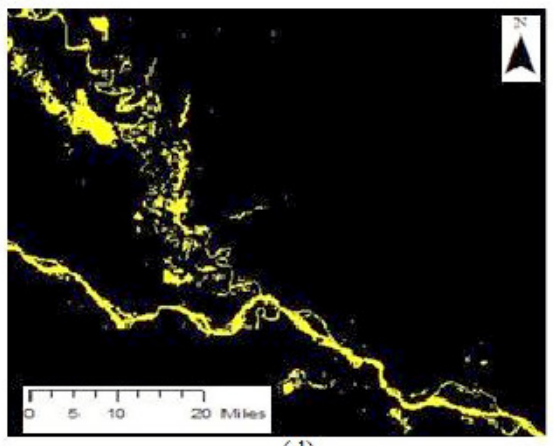

(d)

Figure 13: Water layer detection using cascade-forward back-propagation neural network on (a). $13^{\text {th }}$ August, (b). $25^{\text {th }}$ August, (c). $28^{\text {th }}$ August and (d). $9^{\text {th }}$ September 2017 respectively

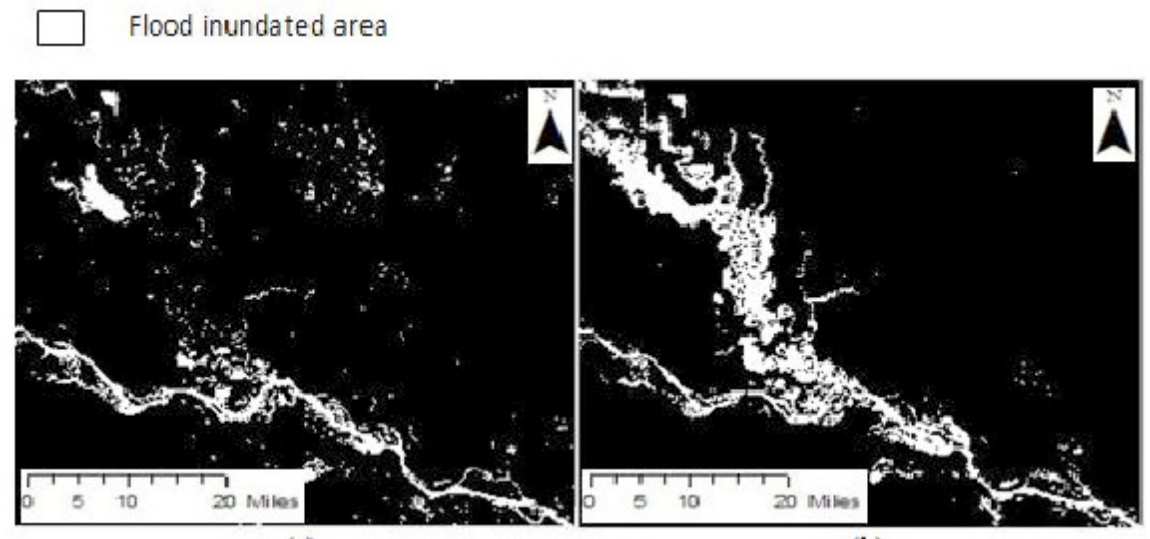

(a)

(b)

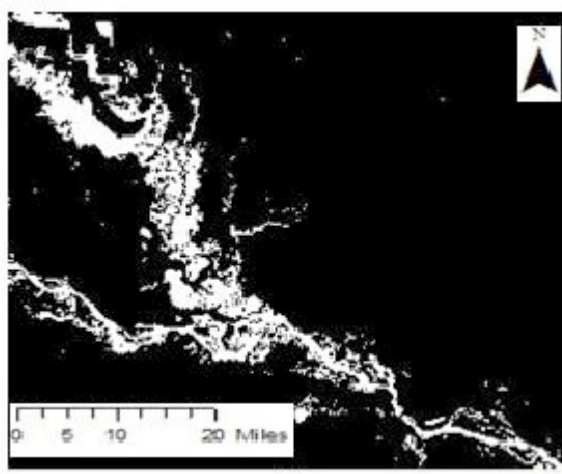

(c)

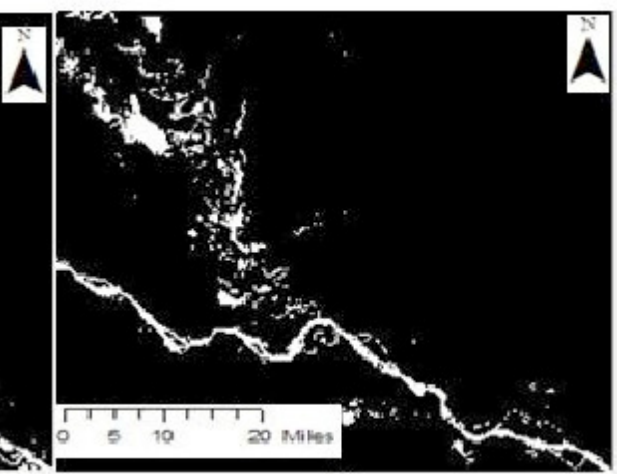

(d)

Figure 14: Flood area detection by cascade-forward back-propagation neural network on (a). $13^{\text {th }}$ August, (b). $25^{\text {th }}$ August, (c). $28^{\text {th }}$ August and (d). $9^{\text {th }}$ September 2017 respectively 
Table 6: Total flood area detected by two neural network algorithms

\begin{tabular}{|c|c|c|}
\hline \multirow[b]{2}{*}{ Date } & \multicolumn{2}{|c|}{ Algorithm } \\
\hline & $\begin{array}{l}\text { By Feed-Forward Neural } \\
\text { Network (in sq. km) }\end{array}$ & $\begin{array}{l}\text { By Cascade-forward back- } \\
\text { propagation neural network } \\
\text { (in sq. } \mathrm{km} \text { ) }\end{array}$ \\
\hline $\begin{array}{l}13^{\text {th }} \text { August } 2017 \\
\text { (During flood) }\end{array}$ & 229.67 & 216.005 \\
\hline $\begin{array}{l}25^{\text {th }} \text { August } 2017 \\
\text { (During flood) }\end{array}$ & 379.82 & 353.809 \\
\hline $\begin{array}{l}28^{\text {th }} \text { August } 2017 \\
\text { (During flood) }\end{array}$ & 485.63 & 458.07 \\
\hline $\begin{array}{l}9^{\text {th }} \text { September } 2017 \\
\text { (post flood) }\end{array}$ & 172.61 & 166.97 \\
\hline
\end{tabular}

Table 7: Performance comparison of feed-forward neural network with traditional method

\begin{tabular}{|l|c|c|c|}
\hline \multicolumn{1}{|c|}{ Parameter } & $\begin{array}{c}\text { Results from Bi- } \\
\text { nary thresholding } \\
\text { technique with GIS } \\
\text { tool (Source: [24]) }\end{array}$ & $\begin{array}{c}\text { Results from } \\
\text { Feed-Forward } \\
\text { Neural Network }\end{array}$ & $\begin{array}{c}\text { Accuracy } \\
\text { in \% }\end{array}$ \\
\hline $\begin{array}{l}\text { Total Flooded area de- } \\
\text { tected in sq. km } \\
\text { on } 13^{\text {th August 2017 }} \\
\text { (During flood) }\end{array}$ & 237.066 & 229.67 & 96.88 \\
\hline $\begin{array}{l}\text { Total Flooded area de- } \\
\text { tected in sq. km } \\
\text { on 25 August 2017 } \\
\text { (During flood) }\end{array}$ & 392.098 & 379.82 & 96.87 \\
\hline $\begin{array}{l}\text { Total Flooded area de- } \\
\text { tected in sq. km } \\
\text { on 28 August 2017 } \\
\text { (During flood) }\end{array}$ & 498.472 & & 97.42 \\
\hline
\end{tabular}

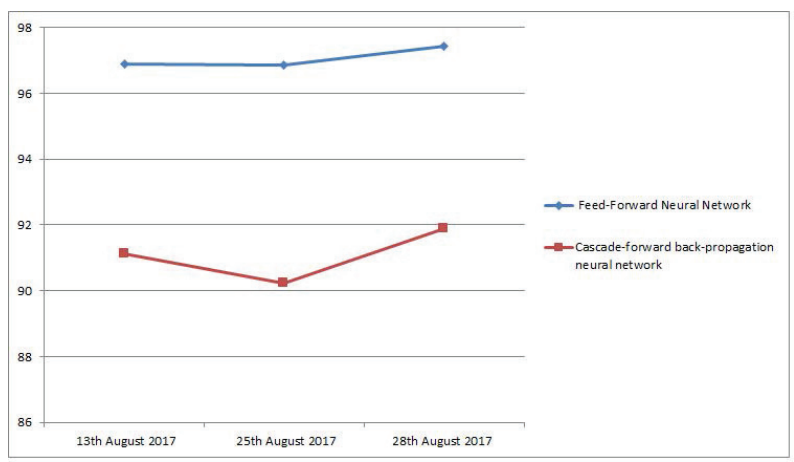

Figure 15: Comparison of accuracy of the two neural network algorithms 


\section{Conclusion}

Remote sensing data is an active source for disaster detection. In the monitoring of flood disaster, extracting flooded area is of utmost importance. It forms the basis for calculating the flood impacted area, evaluation of loss of human and animal lives, reconstruction of flood-hit area. As SAR data is not influenced by weather, season factor, day and night and has high temporal resolution, it is widely used in disaster management. The flood impacted area in the state of Uttar Pradesh, India is chosen as the study area. In this paper, automatic detection of flood area effectively using the machine learning algorithms Feed-Forward Neural Network and Cascade-Forward Back-Propagation neural network is discussed using multi-temporal Sentinel-1 imagery. A two-layer feed-forward network, with sigmoid hidden and linear output neurons is designed for Feed-Forward Neural Network, Cascade-forward backpropagation neural network using MATLAB R2018b. Neural network stores information in terms of weights i.e., to train the neural network with new information, weights are modified. Training performance of a neural network is evaluated using its MSE and regression analysis. Compared the time complexities of the two neural network algorithms. The two neural network algorithms are observed to give similar results with respect to water layer extraction. The highlighted region (in white) is the flood affected region. Flood area on different flood dates is calculated in sq. $\mathrm{km}$ for the two machine learning models. Since ground truth image of the study area is not available, results from Binary thresholding technique with GIS tool is used as a reference for flood area calculation. The flood area assessment obtained by Feed-Forward Neural Network matches closely with that fetched from standard source (Binary thresholding technique using GIS tool). The accuracy ( $97 \%$ ) thus obtained confirms that Feed-Forward Neural Network yields better results in calculating the extent of the flooded area for disaster management purposes.

\section{Acknowledgments}

The first author would like to thank the Disaster \& Management division, National Remote Sensing Centre (NRSC), Hyderabad for sharing knowledge about working on real-time SAR images. The authors would like to thank European Space Agency (ESA) for providing Sentinel-1 data products.

\section{Author contributions}

The first author performed the analysis and design, processed the experimental data, and drafted the manuscript. Second author encouraged and supervised the findings of this work.

\section{Conflict of interest}

The authors declare no conflict of interest.

\section{References}

[1] Amit, S.N.K.B.; Aoki, Y. (2017). Disaster detection from aerial imagery with convolutional neural network, Proc. - International Electronics Symposium on Knowledge Creation and Intelligent Computing, IES-KCIC 2017, 239-245, 2017.

[2] Arvind, S. (2015). Floods in India: Causes and Control, [Online]. Available: https://www.techgape.com/2015/07/floods-causes-and-control.html, Accesed on 25 February 2019.

[3] Bhatt, C. M.; Rao, G. S. (2016). Ganga floods of 2010 in Uttar Pradesh, north India: a perspective analysis using satellite remote sensing data, Geomatics, Nat. Hazards Risk, 7(2), 747-763, 2016.

[4] Bhatt, C. M.; Rao, G. S.; Farooq, M.; Manjusree, P.; Shukla, A.; Sharma, S. V.S.P.; Kulkarni, S. S.; Begum, A.; Bhanumurthy, V.; Diwakar, P. G.; Dadhwal, V. K. (2017). Satellite-based assessment of the catastrophic Jhelum floods of September 2014, Jammu \& Kashmir, India, Geomatics, Nat. Hazards Risk, 8(2), 309-327, 2017. 
[5] Bhatt, C. M.; Srinivasa Rao, G., Begum, Asiya; Manjusree, P.; Sharma, S. V.S.P.; Prasanna, L.; Bhanumurthy, V. (2013). Satellite images for extraction of flood disaster footprints and assessing the disaster impact: Brahmaputra floods of June-July 2012, Assam, India, Curr. Sci., 104(12), 1692-1700, 2013.

[6] Brakenridge, R.; Anderson, E.(2006). Modis-Based Flood Detection, Mapping and Measurement: the Potential for Operational Hydrological Applications, Transbound. Floods Reducing Risks Through Flood Manag., 72, 1-12, 2006.

[7] Brezonik, P.; Menken, K. D.; Bauer, M..(2005). Landsat-based remote sensing of lake water quality characteristics, including chlorophyll and colored dissolved organic matter (CDOM), Lake Reserv. Manag., 21(4), 373-382, 2005.

[8] Ceyhun, Ö.; Yalçin, A.(2010). Remote sensing of water depths in shallow waters via artificial neural networks, Estuar. Coast. Shelf Sci., 89(1), 89-96, 2010.

[9] Clement, M. A.; Kilsby, C. G.; Moore, P.(2017). Multi-Temporal SAR Flood Mapping using Change Detection, J. Flood Risk Manag., 11(2), 1-17, 2017.

[10] D'Addabbo, A.; Refice, A.; Pasquariello, G.; Lovergine, F.(2016). SAR/optical data fusion for flood detection, Int. Geosci. Remote Sens. Symp., 7631-7634, 2016.

[11] Faiza, B.; Yuhaniz, S. S.; Mohd Hashim, S. Z.; Kalema, A. K. (2012). Detecting floods using an object based change detection approach, Int. Conf. Comput. Commun. Eng., 44-50, 2012.

[12] Grimaldi, S.; Xu, J.; Li, Y.; Pauwels, V.R.N.; Walker, J. P. (2020). Flood mapping under vegetation using single SAR acquisitions, Remote Sens. Environ., 237, 2020.

[13] Heege, T.; Kiselev, V.; Wettle, M.; Hung, N. N. (2014). Operational multi-sensor monitoring of turbidity for the entire Mekong Delta, Int. J. Remote Sens., 35(8), 2910-2926, 2014.

[14] Hostache, R.; Matgen, P.; Wagner, W. (2012). Change detection approaches for flood extent mapping: How to select the most adequate reference image from online archives?, Int. J. Appl. Earth Obs. Geoinf., 19(1), 205-213. 2012.

[15] Jay, S.; Guillaume, M. (2014). A novel maximum likelihood based method for mapping depth and water quality from hyperspectral remote-sensing data, Remote Sens. Environ., 147, 121-132, 2014.

[16] Jebur, A. A.; Atherton, W.; Al Khaddar, R. M.; Aljanabi, K. R. (2019). Performance analysis of an evolutionary LM algorithm to model the load-settlement response of steel piles embedded in sandy soil, Meas. J. Int. Meas. Confed., 140, 622-635, 2019.

[17] Jensen, J. R. (2013). Remote sensing of the environment: An earth resource perspective, 2/e, Pearson Education India, 2013.

[18] Kaku, K.; Held, A. (2013). Sentinel Asia: A space-based disaster management support system in the Asia-Pacific region, Int. J. Disaster Risk Reduct., 6, 1-17, 2013.

[19] Klemas, V. (2015). Remote Sensing of Floods and Flood-Prone Areas: An Overview, J. Coast. Res., 31(4), 1005-1013, 2015.

[20] Maddox, I. (2014). Three Common Types of Flood Explained, [Online]. Available: https://www.intermap.com/risks-of-hazard-blog/three-common-types-of-flood-explained, Accesed on 05 March 2019.

[21] Martinis, S.; Kuenzer, C.; Wendleder, A.; Huth, J.; and Twele, A.; Roth, A.; Dech, S. (2015). Comparing four operational SAR-based water and flood detection approaches, Int. J. Remote Sens., 36(13), 3519-3543, 2015. 
[22] Matikainen, L.; Hyyppä, J.; Kaartinen, H. (2014). Automatic detection of changes from laser scanner and aerial image data for updating building maps, Int. Arch. Photogramm. Remote Sens. Spat. Inf. Sci. - ISPRS Arch., 35, 434-439, 2004.

[23] Nallapareddy, A.; Balakrishnan, B. (2019a). Despeckling of synthetic aperture radar satellite imagery using various filtering techniques, ARPN J. Eng. Appl. Sci., 14(19), 3401-3407, 2019.

[24] Nallapareddy, A.; Balakrishnan, B. (2019b). Flood detection and flood mapping using multitemporal synthetic aperture radar and optical data, Egypt. J. Remote Sens. Sp. Sci., 1-13, 2019.

[25] Nallapareddy, A.; Balakrishnan, B. (2019c). Change Detection and Flood Water Mapping Using Sentinel-1A Synthetic Aperture Radar Images, J. Comput. Theor. Nanosci., 16(8), 3544-3549, 2019 .

[26] Rahman, M. R.; Thakur, P. K. (2018). Detecting, mapping and analysing of flood water propagation using synthetic aperture radar (SAR) satellite data and GIS: A case study from the Kendrapara District of Orissa State of India, Egypt. J. Remote Sens. Sp. Sci., 21(1), S37-S41, 2018.

[27] Sanyal, J.; Lu, X. X. (2004). Application of Remote Sensing in Flood Management with Special Reference to Monsoon Asia: A Review, Nat. Hazards, 33, 283-301, 2004.

[28] Schumann, G. J.P.; Moller, D. K. (2015). Microwave remote sensing of flood inundation, Phys. Chem. Earth, 83-84, 84-95, 2015.

[29] Sitharthan, R. Devabalaji, K. R.; Jees, A. (2017). An Levenberg-Marquardt trained feed-forward back-propagation based intelligent pitch angle controller for wind generation system, Renew. Energy Focus, 22-23, 24-32, 2017.

[30] Sumer, E.; Celebi, F. V. (2006). Detection of tsunami induced changes from high resolution satellite imagery, Proc. - Ocean. 2006 - Asia Pacific, 1-7, 2006.

[31] Tanguy, M.; Chokmani, K.; Bernier, M.; Poulin, J.; Raymond, S. (2017). River flood mapping in urban areas combining Radarsat-2 data and flood return period data, Remote Sens. Environ., 198, 442-459, 2017.

[32] Vu, T. T.; Matsuoka, M.; Yamazaki, F. (2004). LIDAR-based change detection of buildings in dense urban areas, Int. Geosci. Remote Sens. Symp., 5, 3413-3416, 2004.

[33] Yang, S.; Ting, T. O.; Man, K. L.; Guan, S. U. (2013). Investigation of neural networks for function approximation, Procedia Comput. Sci., 17, 586-594, 2013.

[34] Yonghua, S.; Xiaojuan, L.; Huili, G.; Wenji, Z.; Zhaoning, G. (2007). A study on optical and SAR data fusion for extracting flooded area, Int. Geosci. Remote Sens. Symp., 3086-3089, 2007.

[35] [Online]. Asian Disaster Reduction Centre (2011). Natural Disaster Data Book 2011, Available: http://www.adrc.asia/publications/databook/ORG/databook_2011/pdf/DataBook2011_e.pdf, Accesed on 18 December 2018.

[36] [Online]. ESA (2020a). User Guides -Sentinel-1 SAR - Naming Conventions - Sentinel Online, Available: https://sentinel.esa.int/web/sentinel/user-guides/sentinel-1-sar/naming-conventions, Accesed on 25 February 2019.

[37] [Online]. ESA (2020b). User Guides - Sentinel-1 SAR - Revisit and Coverage - Sentinel Online, Available: https://sentinel.esa.int/web/sentinel/user-guides/sentinel-1-sar/revisit-and-coverage, Accesed on 25 February 2019.

[38] [Online]. ESA (2020c). User Guides - Sentinel-1 SAR - SAFE Specification - Sentinel Online, Available: https://sentinel.esa.int/web/sentinel/user-guides/sentinel-1-sar/dataformats/safe-specification, Accesed on 25 February 2019. 
[39] [Online]. ESA (2020d). User Guides - Sentinel-1 - Instrument Payload - Sentinel Online, Available: https://sentinel.esa.int/web/sentinel/missions/sentinel-1/instrument-payload, Accesed on 25 February 2019.

[40] [Online]. ESA (2020e). User Guides - Sentinel-1 SAR - Level-1 - Sentinel Online, Available: https://sentinel.esa.int/web/sentinel/user-guides/sentinel-1-sar/product-types-processinglevels/level-1, Accesed on 25 February 2019.

[41] [Online]. Firstpost (2017). Uttar Pradesh floods: Death toll rises to 104; over 28 lakh across 24 districts affected, Available: https://www.firstpost.com/india/uttar-pradesh-floods-death-tollrises-to-103-over-28-lakh-across-24-districts-affected-3992853.html, Accesed on 25 February 2019.

[42] [Online]. Floods in India Essay (2017). Available: http://sneakers360.net/floods-in-india-essay/, Accesed on 22 February 2019.

[43] [Online]. India-WRIS (2017). India-wris webgis water resource information system of india, Available: http://indiawris.gov.in/wris/\#/, Accesed on 10 March 2019.

[44] [Online]. Hindustan-Times (2017) Two more dams damaged in Gorakhpur, Uttar Pradesh CM surveys flood-affected areas, Available: https://www.hindustantimes.com/lucknow/twomore-dams-damaged-in-gorakhpur-uttar-pradesh-cm-surveys-flood-affected-areas/storyaPy1ARk3Jn6S7NQE8CfMwJ.html, Accesed on 10 March 2019.

[45] [Online]. Matlab. (2019). What is a neural network?, Available: https://in.mathworks.com/discovery/neural-network.html, Accesed on 25 February 2019.

[46] [Online]. Water Directors. (2011). Floods Directive (2007/60/EC): Reporting sheets, Series. 1, Issue: February 2011, pp. 1-25, 2011. Available: https://www.ec.europa.eu/environment/water/flood_risk/key_docs.htm\#Directive/, Accesed on 26 February 2019.

[47] [Online]. World Bank (2017). As Natural Disasters Rise, Countries Call for Action on Resilient Crisis Recovery Planning. Available: https://www.worldbank.org/en/news/feature/2017/06/06/asnatural-disasters-rise-countries-call-for-action-on-resilient-crisis-recovery-planning/, Accesed on 16 June 2019.

\section{(2) $(1) \Theta$}

Copyright (C)2020 by the authors. Licensee Agora University, Oradea, Romania.

This is an open access article distributed under the terms and conditions of the Creative Commons Attribution-NonCommercial 4.0 International License.

Journal's webpage: http://univagora.ro/jour/index.php/ijccc/

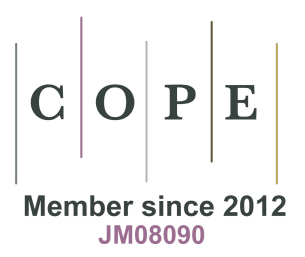

This journal is a member of, and subscribes to the principles of, the Committee on Publication Ethics (COPE).

https://publicationethics.org/members/international-journal-computers-communications-and-control

Cite this paper as:

Nallapareddy, A.; Balakrishnan, B. (2020). Automatic Flood Detection in Multi-Temporal Sentinel1 Synthetic Aperture Radar Imagery Using ANN Algorithms, International Journal of Computers Communications \& Control, 15(3), 3816, 2020.

https://doi.org/10.15837/ijccc.2020.3.3816 